Perfil Hematológico em Cães Infectados Naturalmente por Cinomose com Presença de Corpúsculo de Sinegaglia Lentz, em Vassouras - RJ

Acácia Ferreira Vicente, Ana Paula Martinez de Abreu, Alvaro Alberto Moura Sá dos Passos

Parasitologia

\title{
Perfil Hematológico em Cães Infectados Naturalmente por Cinomose com Presença de Corpúsculo de Sinegaglia Lentz, em Vassouras - RJ
}

\author{
Acácia Ferreira Vicente ${ }^{1}$, Ana Paula Martinez de Abreu², \\ Alvaro Alberto Moura Sá dos Passos ${ }^{3}$ \\ 1 Universidade Severino Sombra, Medicina Veterinária, \\ acaciavicente@hotmail.com \\ 2 Universidade Severino Sombra, Medicina Veterinária, \\ ana_abreuvet@yahoo.com.br \\ 3 Universidade Severino Sombra, Medicina Veterinária, \\ alvaroalbertopassos@hotmail.com
}

Resumo: em trinta cães atendidos no Hospital Veterinário da Universidade Severino Sombra, com sinais clínicos e corpúsculos de inclusão de Sinegaglia Lentz em células sanguíneas, foram observadas as alterações hematológicas de anemia (80\%); leucocitose (13,3\%); leucopenia (10\%); DNNE (33,3\%); neutrofilia (46,7\%); linfopenia (46,7\%); linfocitose (6,7\%); monocitose $(13,3 \%)$ e trombocitopenia (36,7\%). Além disso, observamos que 66,7\% dos casos foram atendidos no verã; $80 \%$ dos animais tinham apenas infecções secundárias no primeiro atendimento; $41 \%$ dos cães não tinham raça definida (SRD) e 86,7 \% dos animais tinham corpúsculo de inclusão vírica em linfócitos.

Palavras-Chave: Hematologia, Cinomose, Sinegaglia Lentz, Canino.

Rev. de Saúde, Vassouras, v. 1, n. 1, p. 49-54, jan./mar., 2010 
Perfil Hematológico em Cães Infectados Naturalmente por Cinomose com Presença de Corpúsculo de Sinegaglia Lentz, em Vassouras - RJ

Acácia Ferreira Vicente, Ana Paula Martinez de Abreu, Alvaro Alberto Moura Sá dos Passos

Parasitologia

\title{
Hematologic Profile in Naturaly Infected Dogs by Cinomosis With Presence of Sinegaglia Lentz Corpuscles, in Vassouras, RJ
}

\begin{abstract}
Hospital Veterinário da Universidade Severino Sombra, with clinical signals and inclusion corpuscles of Sinegaglia Lentz in blood cells, were observed the hematologic of: anemia (80\%), leucocytosis (13.3\%), leucopenia (10\%), DNNE (33.3\%), neutrophilia (46.7\%), lymphopenia (46.7\%), lymphocytosis (6.7\%), monocytosis (13.3\%) and trombocytopenia (36.7\%). It was observed that $66.7 \%$ of the cases were treated in summer, $80 \%$ of the animals had only secondary infections in the first treatment, $41 \%$ of the dogs had not defined race (SRD) and $86.7 \%$ of the animals had corpuscles of inclusion virile in lymphocytes.
\end{abstract}

Keyword: Hematology. Cinomosis. Sinegaglia Lentz. Dog.

\section{Introdução}

Altamente contagiosa, a cinomose canina é considerada uma doença com alta taxa de letalidade, quando comparada a outras doenças infectocontagiosas em cães [Silva et al. 2005; Gebara et al. 2004]. Ademais, esta doença tem sido considerada reemergente em países onde já esteve controlada [Norris et al. 2006]. Pertence ao gênero Morbillivirus e à família Paramixoviridae, este vírus infecta uma grande variedade de carnívoros, mas o cão é seu principal reservatório para o vírus [Moro et al. 2003].

O vírus da cinomose canina (VCC) é um vírus de RNA de fita simples, possui envelope e, como outros morbilivírus, apresenta tropismo por linfócitos, o que conduz à imunossupressão e infecções secundárias [Almeida et al. 2009].

De $25 \%$ a $75 \%$ dos animais susceptíveis desenvolvem infecção subclínica e eliminam o vírus no ambiente o que constitui fontes de infecção [Gebara et al. 2004]. A transmissão ocorre por contato direto ou por meio de aerossóis [Quinn et al. 2005].

Os principais sinais clínicos são as secreções oculares e nasais, hiperqueratose dos coxins digitais, dermatite pustular, enterite catarral ou hemorrágica [Sonne et al. 2009], e sinais neurológicos como convulsões, paralisia dos membros pélvicos, ataxia, nistagma, tremores e hipermetria [Gebara et al. 2004].

O vírus se replica no trato respiratório superior do animal, logo se dissemina e também se replica nos sistemas gastrointestinal, urinário e nervoso central, podendo também ocorrer disseminação para a pele [Quinn et al. 2006]. Os corpúsculos de inclusão da cinomose podem ser observados nos epitélios do estômago, pelve renal, pulmão, bexiga, conjuntiva, coxins digitais e em células do sistema nervoso central. [Sonne et al 2009]

A maioria dos diagnósticos é feita com base no histórico, sintomatologia, achados hematológicos e inclusão de Lentz. [Mendonça et al. 2000].

Rev. de Saúde, Vassouras, v. 1, n. 1, p. 49-54, jan./mar., 2010 
Perfil Hematológico em Cães Infectados Naturalmente por Cinomose com Presença de Corpúsculo de Sinegaglia Lentz, em Vassouras - RJ

Acácia Ferreira Vicente, Ana Paula Martinez de Abreu, Alvaro Alberto Moura Sá dos Passos

Parasitologia

Nos hemogramas, os principais achados em cães são linfopenia, anemia e trombocitopenia. No final da primeira semana após a infecção, os animais podem apresentar discreta neutropenia. Na presença de infecção bacteriana secundária, observa-se neutrofilia [Almeida et al 2009] e monocitose [Tudury et al. 1997].

O objetivo deste trabalho foi traçar um perfil hematológico de cães infectados naturalmente pelo vírus da cinomose, confirmada pela presença de corpúsculo de inclusão, Sinegaglia Lentz, em leucócitos ou hemácias, bem como verificar as raças e as idades acometidas com maior freqüência no Município de Vassouras, RJ.

\section{Material e métodos}

Foram atendidos no Hospital Veterinário da Universidade Severino Sombra em Vassouras, trinta cães suspeitos clinicamente de apresentarem a infecção por cinomose durante o período de janeiro de 2009 a janeiro de 2010.

Para a confirmação do diagnóstico foi coletado aproximadamente $3 \mathrm{ml}$ de sangue total com seringa de $3 \mathrm{ml}$ e agulha 25 x 6mm, em veia cefálica ou safena, e acondicionado em tubo com anticoagulante EDTA, com as amostras analisadas no mesmo dia.

O hemograma foi feito manualmente, com hematócrito centrifugado em microcentrífuga durante 5 minutos a $11500 \mathrm{rpm}$ e verificada a porcentagem em régua de microhematócrito. A leucometria global foi realizada em câmara de Newbauer improved, através da diluição de 1:20 em líquido de Türk e a leucometria específica foi realizada através da hematoscopia, em esfregaço sanguíneo corado em panótico rápido.

Os dados foram organizados em uma planilha de excel, com a finalidade de verificar a frequência e gerar gráficos das principais raças e idades acometidas, bem como verificar as principais alterações hematológicas em hemogramas, com a presença da inclusão vírica da cinomose, Sinegaglia Lentz.

\section{Resultado e Discussão}

Dos trinta cães estudados e infectados naturalmente por cinomose, $20(66,6 \%)$ foram atendidos durante o verão. A maioria dos animais, $n=24(80 \%)$, foi levado à clínica com quadro de infecção, secundária como otite, conjuntivite e diarréia.

Menos de $20 \%$ dos animais tinham alteração em sistema respiratório e nervoso associado a outras infecções.

As raças observadas com mais freqüência foram os SRD (sem raça definida), 12 animais infectados (41\%); seguido de Poodle, 6 (21\%); o que corrobora com Sonne et al. (2009). Foi possível observar que outras raças como labrador 4 (13\%) e Beagle, 3 $(10 \%)$, também tinham uma representação significativa quando comparada às outras raças (pinscher, rotweiller, dálmata, basset e husky), que apresentaram apenas um animal, cada.

Rev. de Saúde, Vassouras, v. 1, n. 1, p. 49-54, jan./mar., 2010 
Perfil Hematológico em Cães Infectados Naturalmente por Cinomose com Presença de Corpúsculo de Sinegaglia Lentz, em Vassouras - RJ

Acácia Ferreira Vicente, Ana Paula Martinez de Abreu, Alvaro Alberto Moura Sá dos Passos

Parasitologia

Dos animais estudados, $15(50 \%)$ apresentam mais de 1 ano de idade (adulto) e 11 $(36,6 \%)$ têm menos ou igual a 4 meses de idade, o que discorda de Sonne et al. (2009), que relatam em seus estudos uma maior frequência de filhotes do que de adultos.

As inclusões víricas foram observadas com mais frequência em linfócitos $(86,7 \%)$, o que concorda com o relato de Jain (1993) e discorda de Silva et al. (2005) que observaram em neutrófilos. Neste estudo observamos ainda a presença de corpúsculo de inclusão em hemácias e monócitos, porém, com menor freqüência que as outras células.

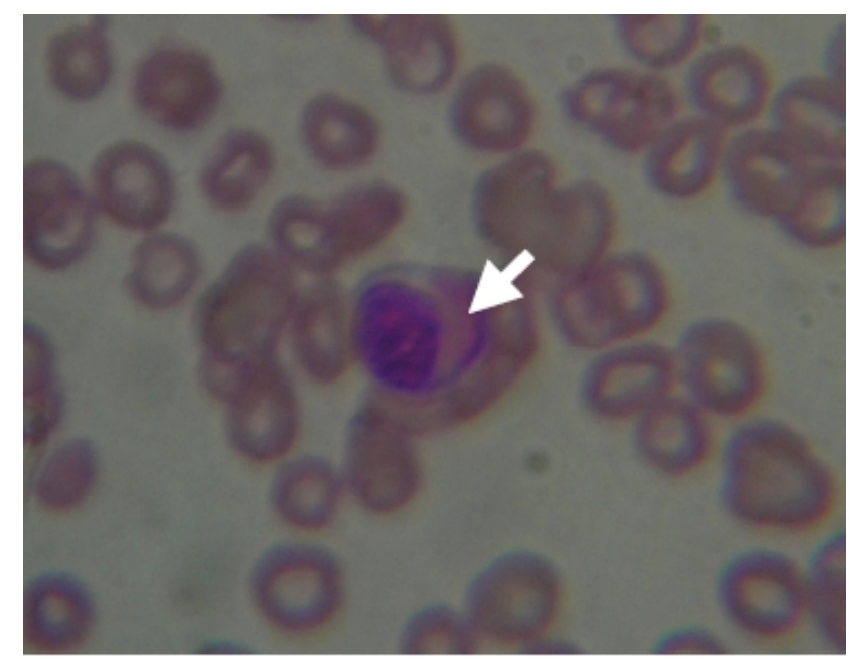

Figura 1. Corpúsculo de inclusão, Sinegaglia Lentz, em citoplasma de linfócito (Fonte: ABREU, A. P. M.)

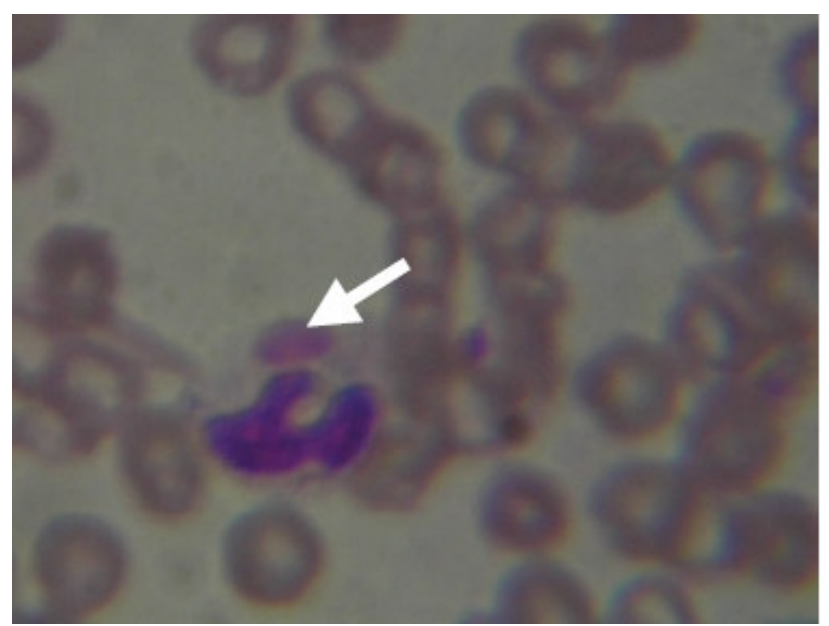

Figura 2. Corpúsculo de inclusão, Sinegaglia Lentz, em citoplasma de neutrófilo. (Fonte: ABREU, A. P. M.) 
Perfil Hematológico em Cães Infectados Naturalmente por Cinomose com Presença de Corpúsculo de Sinegaglia Lentz, em Vassouras - RJ

Acácia Ferreira Vicente, Ana Paula Martinez de Abreu, Alvaro Alberto Moura Sá dos Passos

Parasitologia

Durante o hemograma observou-se que $24(80 \%)$ dos trinta animais estavam anêmicos, o que corrobora com Tudury et al (1997), Silva et al. (2005) e Almeida et al. (2009) que, em seus artigos, também observaram a grande frequência de animais anêmicos, devido à grande destruição dos eritrócitos pelo vírus ou à não produção de hemácias pela medula óssea [Silva et al 2005].

Na leucometria global, 13,3\% apresentaram considerável aumento, ou seja, leucocitose, o que caracteriza uma infecção ou inflamação. E apenas três (10\%) animais tinham leucopenia.

Em relação à leucometria específica, notou-se que quatro animais apresentaram eosinofilia, provavelmente relacionada à verminose, já que eram animais não vermifugados.

Foi observado também, que dez $(33,3 \%)$ animais apresentaram discreto à moderado desvio nuclear neutrofílico à esquerda (DNNE), o que também foi visualizado por Silva et al. (2005), porém quatorze $(46,7 \%)$ apresentaram neutrofilia. Acreditase que o DNNE e a leucocitose estão relacionados com infecções bacterianas oportunistas associadas à infecção pelo vírus da cinomose [Silva et al. 2005; Almeida et al 2009].

Em relação à contagem de linfócitos, quatorze (46,7\%) cães apresentaram linfopenia, nem sempre relacionada à neutrofilia, o que corrobora com Tudury et al. (1997) e Almeida et al. (2009). E apenas dois (6,7\%) tiveram linfocitose.

$\mathrm{Na}$ contagem de monócitos, pode-se notar que apenas quatorze $(13,3 \%)$ animais tiveram monocitose, um deles com infecção por Ehrlichia sp associada à cinomose.

Na contagem total de plaquetas tivemos onze $(36,7 \%)$ animais com trombocitopenia, o que corrobora com Silva et al. (2005) ao sugeririam que isto ocorre por um processo imunomediado com retirada das plaquetas da circulação, através dos macrófagos. E apenas um animal com trombocitose.

\section{Conclusão}

Com base nos dados desta investigação, as alterações hematológicas de anemia, leucopenia, neutrofilia com DNNE e trombocitopenia, foram significativas e podem ser utilizadas pelos clínicos veterinários como recursos diagnósticos auxiliares na cinomose canina, mas deve ser devidamente confirmada pela presença de corpúsculos de inclusão vírica nas células sanguíneas. 
Perfil Hematológico em Cães Infectados Naturalmente por Cinomose com Presença de Corpúsculo de Sinegaglia Lentz, em Vassouras - RJ

Acácia Ferreira Vicente, Ana Paula Martinez de Abreu, Alvaro Alberto Moura Sá dos Passos

Parasitologia

\section{Referências}

Almeida, R.K., Vasconcelos, A.C., Carneiro, R.A., Paes, P.R.O., Moro, L. (2009). Alterações citológicas do sangue periférico e da medula óssea de cães com cinomose.

Arquivo Brasileiro de Medicina Veterinária e Zootecnia, 61 (6): 1255 -1260. Gebara, C.M.S., Woslacki, S.R., Negrão, F.J., Alfieri, A.A., Alfieri, A.F. (2004). Lesões histológicas no sistema nervoso central de cães com encefalite e diagnóstico molecular da infecção pelo vírus da cinomose canina. Arquivo Brasileiro de Medicina Veterinária e Zootecnia, 56 (2), 168 -174.

Jain, N.C. (1993). Essentials of veterinary hematology. Philadelphia: Lea \& Febiger, 417 p. Mendonça, R.B., Pagani, F.F., Souza, A.M. (2000). Respostas hematológicas em cães naturalmente infectados pelo vírus da cinomose: estudo retrospectivo de casos. Rev. Bras. Ciên. Vet., 7: 114.

Moro, L., Alves, C.M., Santos, F.G.A., Nunes, J.E.S., Carneiro, R.A., Vasconcelos, A.C. (2003). Ocorrência de apoptose em leucócitos no esfregaço de sangue periférico e nos sincícios na infecção in vivo pelo vírus da cinomose canina. Arquivo Brasileiro de Medicina Veterinária e Zootecnia, Belo Horizonte, 55 (1), fev.

Norris, J.M., Krockenberger, M.B., Baird, A.A., Knudsen, G. (2006). Canine distemper:re-emergence of an old enem. Aust. Vet. J., 84: 362-363.

Quinn, P.J., Markey, B.K., Carter, M. E., Donnelly, W.J., Leonard, F.C. (2005). Microbiologia veterinária e doenças infecciosas. Porto Alegre: Artmed, 512p.

Silva, I.N.G., Guedes, M.I.F., Rocha, M.F.G., Medeiros, C.M.O., Oliveira, L.C., Moreira, O.C., Teixeira, M.F.S. (2005). Perfil hematológico $e$ avaliaçãoeletroforética das proteínas séricas de cães com cinomose. Arquivo Brasileiro de Medicina Veterinária e Zootecnia, 57 (1): 136-139.

Sonne, L., Oliveira, E.C., Pescador, C.A., Santos, A.S., Pavarini, S.P., Carissimi, A.S.,

Driemeier, D. (2009). Achados patológicos e imuno-histoquímicos em cães infectados naturalmente pelo vírus da cinomose canina. Pesq. Vet. Bras., 29 (2): 143-149, fev. Tudury, E.A., Arias, M.V.B., Bracarense, A.P.F.L., Megid, J., Junior, R.F.D. (1997).

Observaçãoes clínicas e laboratoriais em cães com cinomose nervosa. Ciência Rural, Santa Maria, 27 (2): 229 - 235. 